\title{
FAILURE ANALYSIS OF SUSPENSION SYSTEM THROUGH BOND GRAPH
}

\author{
ANUPAMA $^{1}$, CHANDAN KUMAR ${ }^{2}$, PRAVEEN MISHRA ${ }^{3}$ \& PANKAJ KUMAR ${ }^{4}$ \\ ${ }^{1}$ Associate Professor, SBAS, Galgotias university, Gr. Noida, UP \\ ${ }^{2}$ Professor, Noida Institute of Engineering and Technology, Gr Noida, UP \\ ${ }^{3}$ Assistant Professor, BIT Mesra, Ranchi, Jharkhand \\ ${ }^{4}$ Pankaj Kumar Consulting Head Navi Mumbai
}

\begin{abstract}
This paper presents the premature failure analysis of suspension system. This area of research has attracted attention of many engineers and researchers. The insufficient deflection is one of the major reasons behind the premature failure of suspension system of a passenger car. Deflection capacity under dynamic condition plays important role in the life of any suspension system. In this work a simulation model has been developed and presented which is capable of finding deflection of a suspension system. By simulating this model one may find deflection under the extremely riding condition at the time of design and manufacturing can be done accordingly. To know the reason behind premature failure one may again simulate the computational model using physical parameter of the system. Analyzing the simulated result one may conclude possible factor behind premature failure. Bond graph is a very good modeling technique in the multi energy domain. Paper includes simulation result for a car model after simulating computational model developed through bond graph technique on Symbol Shakti Sonata software.
\end{abstract}

KEYWORDS: Suspension, Bondgrpah, Simulation, Acceleration, Failure Analysis

Received: Jun 08, 2020; Accepted: Jun 28, 2020; Published: Sep 09, 2020; Paper Id.: IJMPERDJUN20201130

\section{INTRODUCTION}

Suspension system of vehicle is very important part they are responsible to human comfort, vibration free riding, travel frequently without any risk due to good handling, smoothly and easy handling and reduce to accident chances.

The main function of suspension system to absorb shock load and separated the passenger curb to road shock and provided comfort. If many of year's scientists, researchers and engineers was compromised with good handling, ride comfort and stability of vehicle, so finally achieved a good suspension system with the help of two component spring and damper. Spring is use to as a shock absorber at restricted label and damper is provide smoothly released this shock energy. If the various type of suspension system used in modern vehicle but active suspension system is mostly used in passenger cars.

Investigation of dynamic behavior and failure analysis of suspension system had attracted many researchers and engineers. Since more than 10 decades research is continue in this area. Few significant contributions are presented in this paper [4] have presented Analytical results for optimum actively damped suspension under random excitation. In this paper result Design a good suspension system with optimum vibration performance under various road conditions is required task. Over the years, both passive and active suspension systems have been proposed to optimize the vehicle quality.[3] have the author presents theoretical model for 
predicting stress from bending agreed with the stiffness and finite element model within the precision of convergence for the finite element analysis. [10] Author analysis the Very high cycle fatigue (VHCF) properties of newly developed clean spring steel were experimentally examined under rotating bending and axial loading. [2] analyzed the Long-term fatigue tests on shot peened helical compression springs were conducted by means of a special spring fatigue testing machine at 40 $\mathrm{Hz}$. Test springs were made of three different spring materials - oil hardened and tempered $\mathrm{Si}, \mathrm{Cr}$ and $\mathrm{Si}, \mathrm{Cr}, \mathrm{V}$-alloyed valve spring steel and stainless steel. [6] have presented the analysis of elastomeric coating influence on dynamic resonant stresses values in spring is presented in this paper. The appropriate equations determining the effectiveness of dynamic stress reduction in resonant conditions as a function of coating parameters were derived.[1] have proposed An adjustablestiffness actuator composed of two antagonistic non-linear springs is proposed in this paper. The elastic device consists of two pairs of leaf springs working in bending conditions under large displacements.[9] have presented to develop of suspension model with use of quarter/ half/ full car model with controller proportional integral derivative (PID) controller was used. In this paper obtained dynamic behavior of suspension system with help of bond graph technique. After the extensive literature survey may be found very few works on failure analysis through bond graph technique. So developed a half car suspension model with help of mathematical and physical model and also simulated.

\section{METHODOLOGY}

The paper is focused towards premature failure of suspension system modeling is an important area of study. Further shows that new modeling technique like one based on the use of bond graph is becoming popular as it help in several ways like flexibility and extensibility of model and automatic generation and solution of the system equations etc. Bond graph was invented by the Paynter [8] are pictorial representation of essential dynamic of physical system through exchange of power amongst the basic elements the system is composed of and its environment. The basic element of bond graph Inertance (I), Capacitance (C), Resistance (R), Source of flow (SF), Source of effort (SE), Gyrator (GY), Transformer (TF), Constant effort junction (0), Constant flow junction (1) and Time integral of effort (P). The bond graph representation of a system may be constructed in total abstraction from the mathematical model of the system. The bond graph causality concept, presented by Karnopp and Rosenberg [7], orientates the calculus schemes in the system model. This constitutes the physical level of the description contained in the bond graph representation. Karnopp [5]. In this technique used to develop a computational model of suspension system to perform failure analysis of suspension system.

The bond graph modeling technique has been attracted considerable attention of engineer and researcher in modeling and simulation of dynamic system it has ability to model systems with the elements from different energy domain. This ability makes this technique very powerful. Sub models may also be developed using this technique.

\section{COMPUTATION MODEL OF HALF CAR}

Physical parameter such as sprang mass $m_{\mathrm{s}}$ unsprang mass $\mathrm{m}_{\mathrm{us}}$ stiffness of spring $\mathrm{k}_{\mathrm{s}}$ stiffness of tire $\mathrm{k}_{\mathrm{t}}$ damping force of suspension $c_{s}$ damping force of tire $c_{t}$ and road condition to be taken $y$ are consider to developed this model with the help of this physical model in bond graph half car model is perform to various load and road condition such as highly bump are used to develop the model. To analyses the various deflection of suspension at different loading factor and different environment factor. In the figure:1represent half car models in these figure numeric values are used to numbering of half arrow to provide the directional command of flow and effort. 


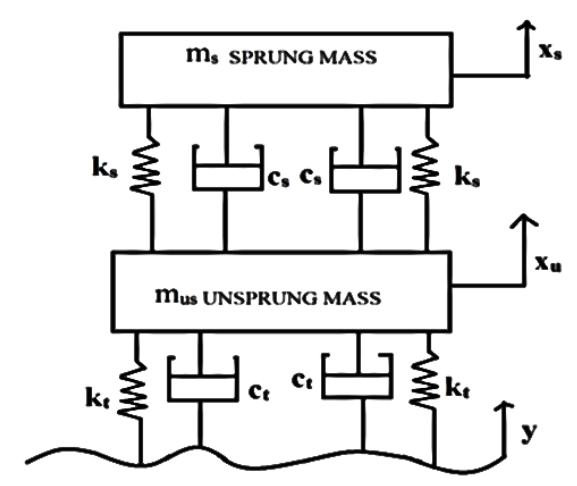

Figure 1: Half Car Physical Models.

Zero is represented constant flow junction and one is represent constant effort junction, $\mathrm{C}$ are represent the stiffness of suspension spring $k_{s}$ and tire stiffness $k_{t}, R$ is represent dampers in suspension system $c_{s}, I$ are represent body sprung mass and unsprang mass of the car, TF are represent transformation of energy in one step to the next step continuously and SF are also represented source of flow of the car .

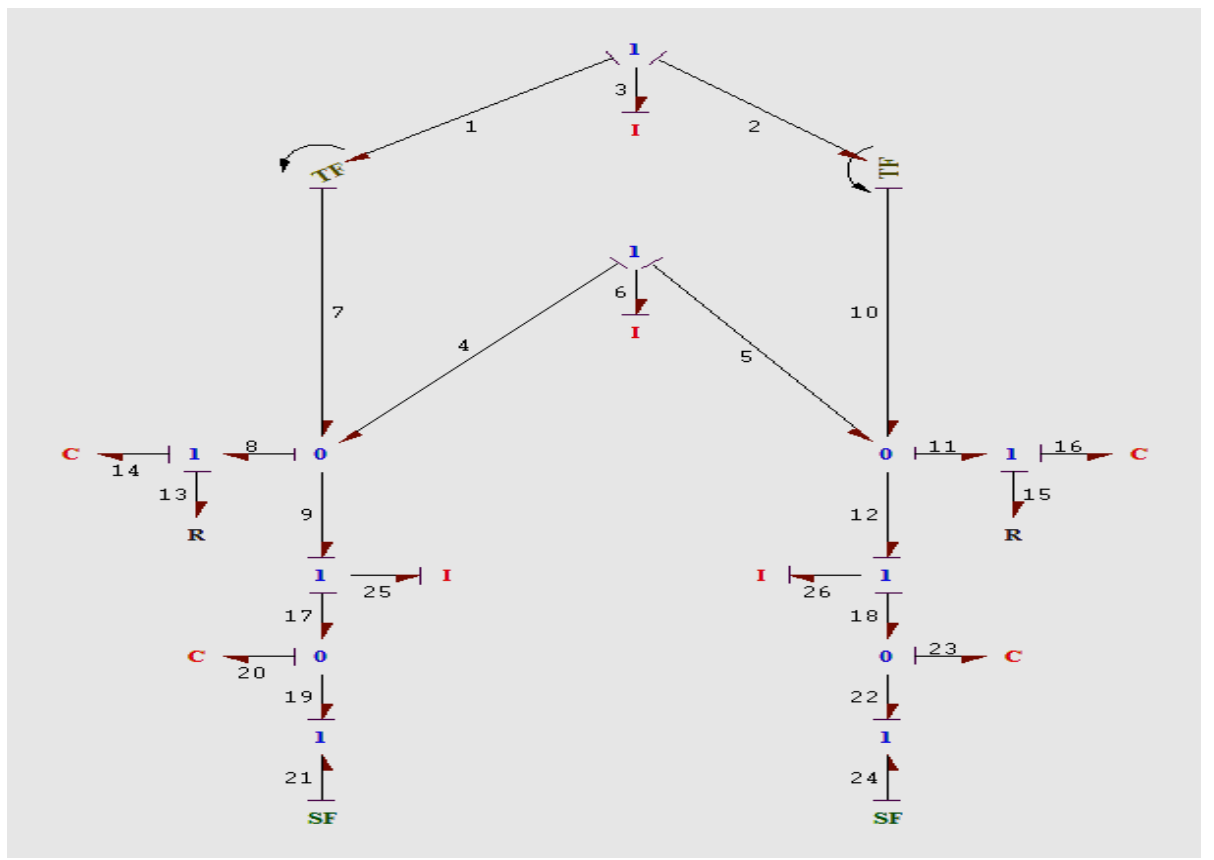

Figure 2: Half Car Model through Bond Graph.

In the figure: $2 \mathrm{C} 14$ is right front suspension spring and $\mathrm{C} 16$ left front suspension spring is indicated, R13 right suspension damper and R15 is left suspension damper, C20 and C23 are tire stiffness right and left of the front of vehicle, I3 and I6 sprung mass of the vehicle, I25 and I26 are vehicle right and left tire mass of the vehicle. In the model put the various speed to obtain the deflection of suspension system and also deflection find out to various load and different road conditions. In this model all the physical design parameter are used to simulation of the suspension system. If the source of effort is the load of body and the source of flow velocity of the car and in this model both are applied to different condition of road such as plain road, bumpy and irregular road to find out its suspension deflection and also find the various load condition such as overloading have been applied to find out the deflection in suspension system. To compared these parameter of the case study data where find the maximum deflection in suspension. If any value of deflection reached at 
various analysis conditions then the design of suspension system have failed and recommended the modification of the design variables.

As a cause study using physical data of suspension system of TATA INDICA car EV2 model has been performed, this model have simulated. The simulation data is taken failure analysis of suspension system as a case study Tata India [11]. The simulation parameters are presented in table: 1 .

Table 1: Simulation Parameter of Half Car Front Suspension System

\begin{tabular}{|c|c|}
\hline Sprung mass & $718.583 \mathrm{Kg}$ \\
\hline Front unsprang mass & $100 \mathrm{Kg}$ \\
\hline Rear unsprang mass & $100 \mathrm{Kg}$ \\
\hline Moment of inertia $\mathrm{I}_{\mathrm{zz}}(\mathrm{X}-\mathrm{Y})$ & $1460.769 \mathrm{Kg}-\mathrm{m}^{2}$ \\
\hline $\mathrm{I}_{\mathrm{yy}}(\mathrm{X}-\mathrm{Z})$ & $1739.092 \mathrm{Kg}-\mathrm{m}^{2}$ \\
\hline $\mathrm{I}_{\mathrm{xx}}(\mathrm{Z}-\mathrm{X})$ & $413.239 \mathrm{Kg}-\mathrm{m}^{2}$ \\
\hline Stiffness of suspension spring & $25.30 \mathrm{KN} / \mathrm{m}$ \\
\hline Stiffness of tire & $182.47 \mathrm{KN} / \mathrm{m}$ \\
\hline Damper force & $2958 \mathrm{~N}-\mathrm{m} / \mathrm{sec}$ \\
\hline Front track width & $1.40 \mathrm{~m}$ \\
\hline Road roughness & \\
\hline
\end{tabular}

After prepared the computational model of half car front suspension system to simulate on the given parameter to be analyzed and find out the graphical representation of the result at various speed and load.
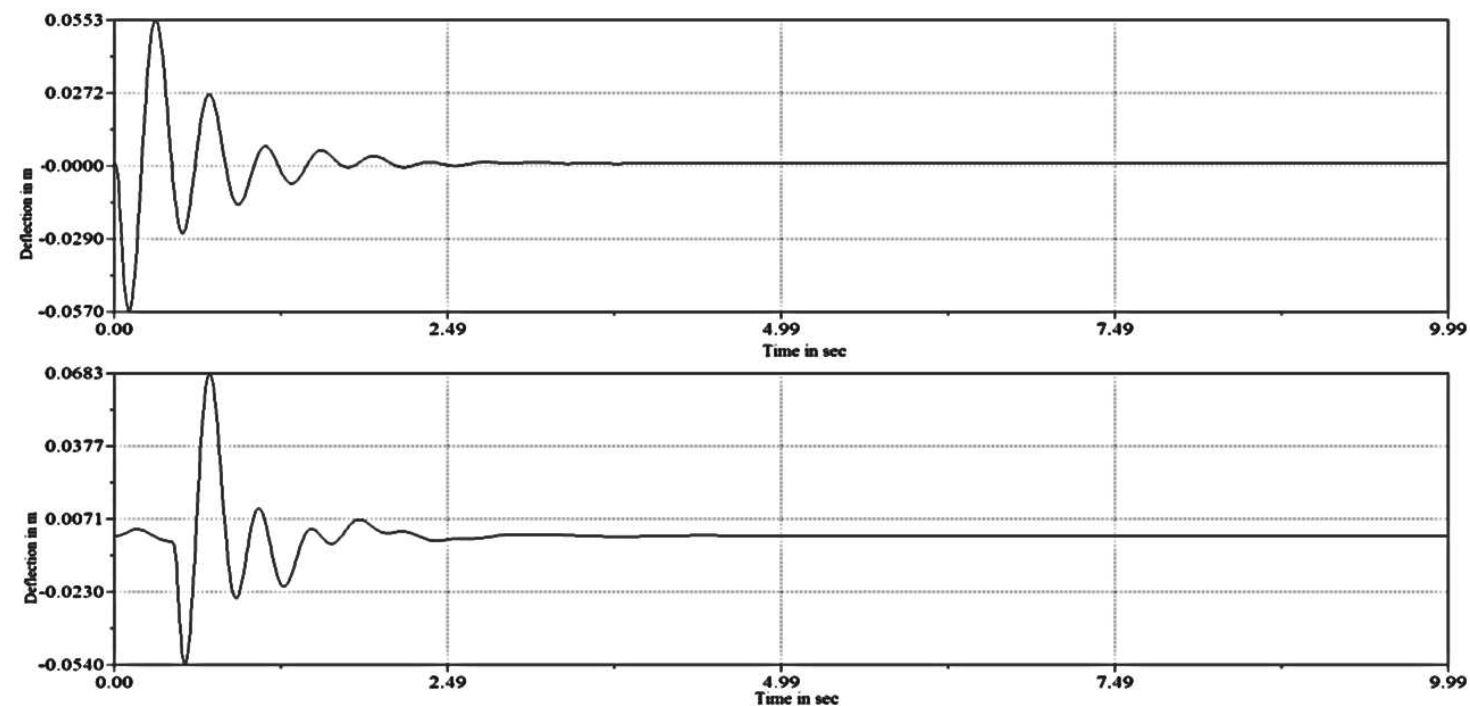

Figure 3: ( a and b ) Deflection at $20 \mathrm{Km} / \mathrm{h}$.

In the figure vehicle velocity $20 \mathrm{Km} / \mathrm{h}$ shown the suspension system are very sensitive to absorbed shock load and to give some time to adjust original position in the figure a vehicle is started to run some deflection in suspension system up to $.5 \mathrm{sec}$ is much but once the vehicle is retain constant speed without any bump so very little deflection in the vehicle because they are due to the running velocity difference. In figure $b$ is shown the vehicle at this speed continuous after some time $.75 \mathrm{sec}$ vehicle passed on a bump these resulting increase deflection quick at $68.3 \mathrm{~mm}$ and restore its on position at $1.25 \mathrm{sec}$. This complete cycle of suspension system is within $.5 \mathrm{sec}$ and completely smooth within $2.49 \mathrm{sec}$. 

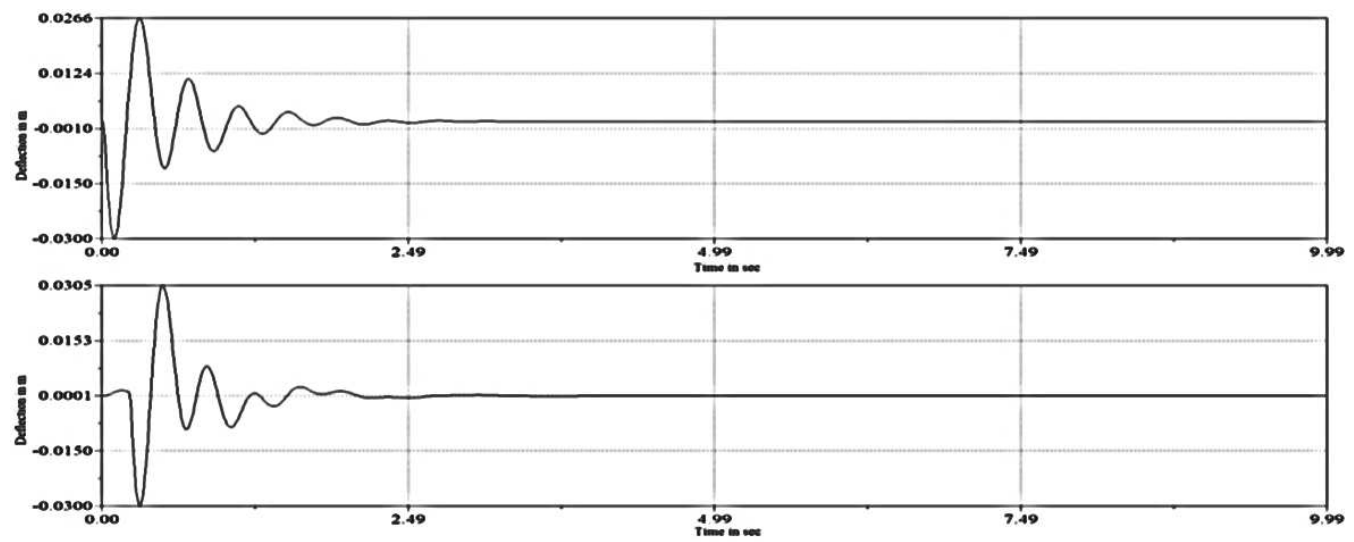

Figure 4: ( a and b) Suspension Deflection at $40 \mathrm{Km} / \mathrm{h}$.

In previous figure speed shown $20 \mathrm{Km} / \mathrm{h}$ and this time speed taken $40 \mathrm{Km} / \mathrm{h}$. In the figure show the deflection reduced at the $40 \mathrm{Km} / \mathrm{h}$ at same bump condition and road condition used. At this velocity very less time required to response the suspension system. In figure d maximum deflection is $30.5 \mathrm{~mm}$ at $.5 \mathrm{sec}$ and next $.25 \mathrm{sec}$ damper respond to retain approximate original position and at $40 \mathrm{Km} / \mathrm{h}$ speed suspension deflection smooth within 2 sec after pass bump. So the next figure speed at $60 \mathrm{Km} / \mathrm{h}$.
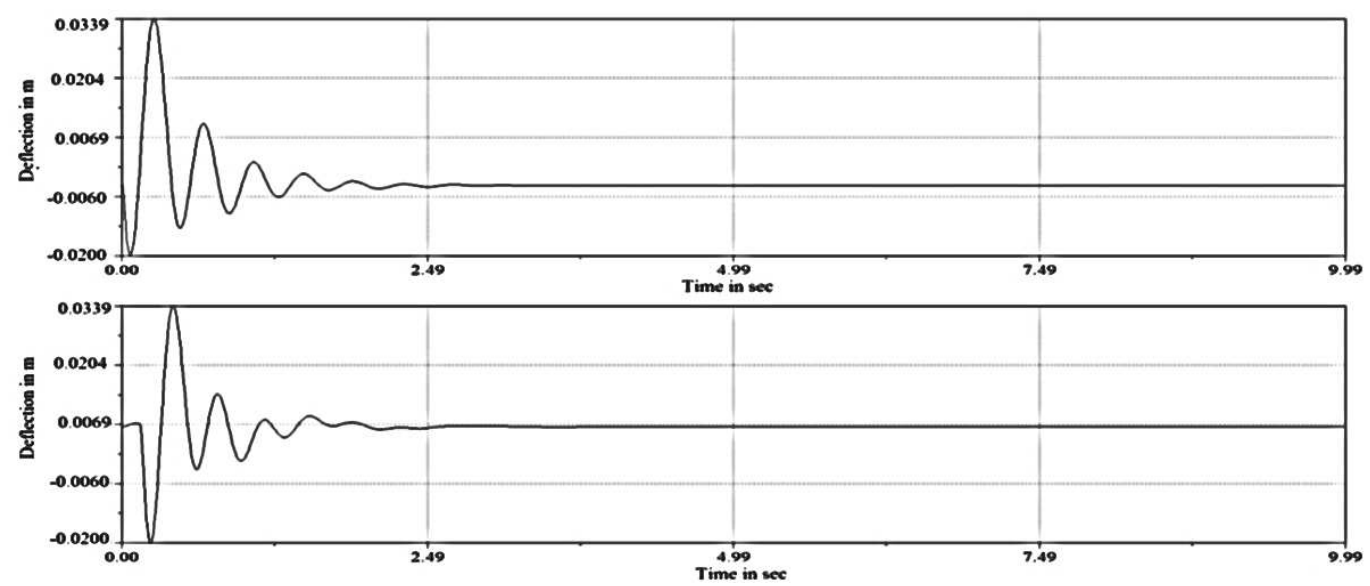

Figure 5: (a and b) Suspension Deflection $60 \mathrm{~km} / \mathrm{h}$.

In this figure suspension deflection increase but time requirement reduce and response to faster compare to $40 \mathrm{Km} / \mathrm{h}$ speed. At $60 \mathrm{Km} / \mathrm{h}$ speeds vehicle suspension deflection $33.9 \mathrm{~mm}$ at less than $.5 \mathrm{sec}$ and return to again $.5 \mathrm{sec}$ at this cycle of suspension system movement to more time consumed to return its original position as compared to deflection reached. 

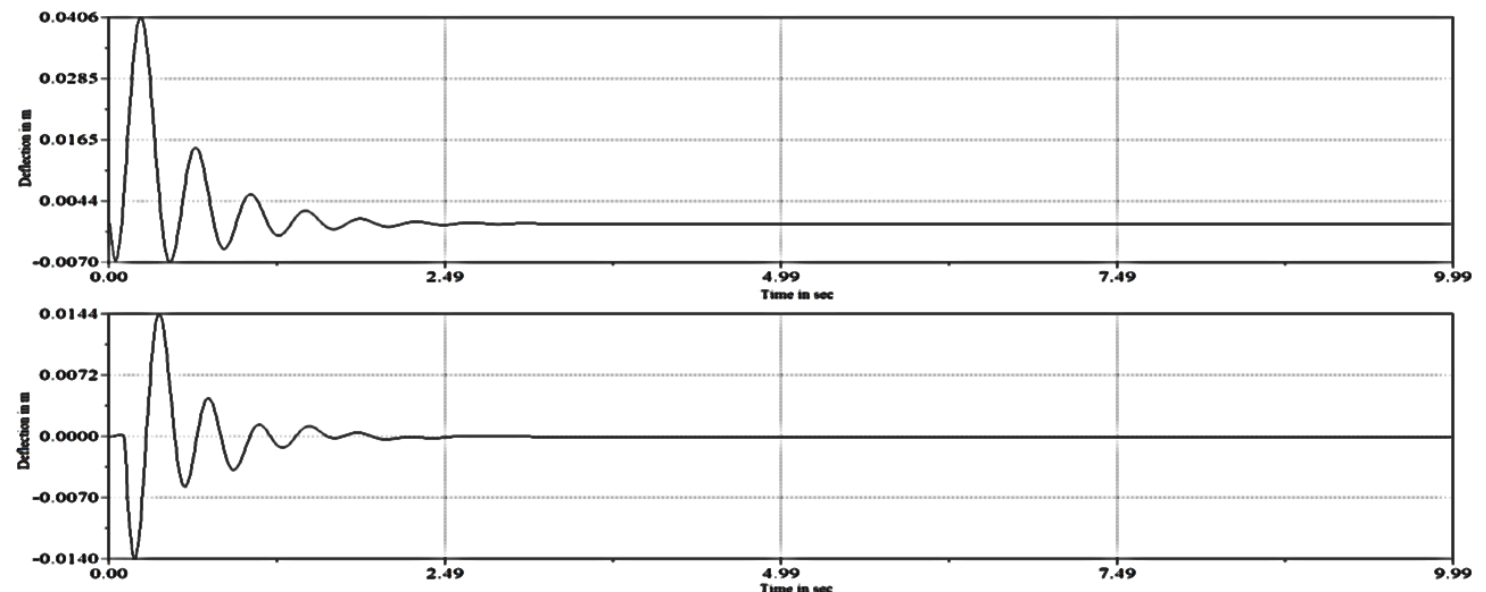

Figure 6: (a and b) Suspension Deflection at 80km per Hour.

In this figure shown the speed of vehicle at $80 \mathrm{Km} / \mathrm{h}$ at this speed deflection is also increase and time taken to reversed is very less. In the figure maximum deflection $40.6 \mathrm{~mm}$ have passed to bump and time taken to reach this position less than $.5 \mathrm{sec}$ again and return to smooth condition after $.5 \mathrm{sec}$. and at this speed vehicle once zero deflection condition shown after $2.5 \mathrm{sec}$.
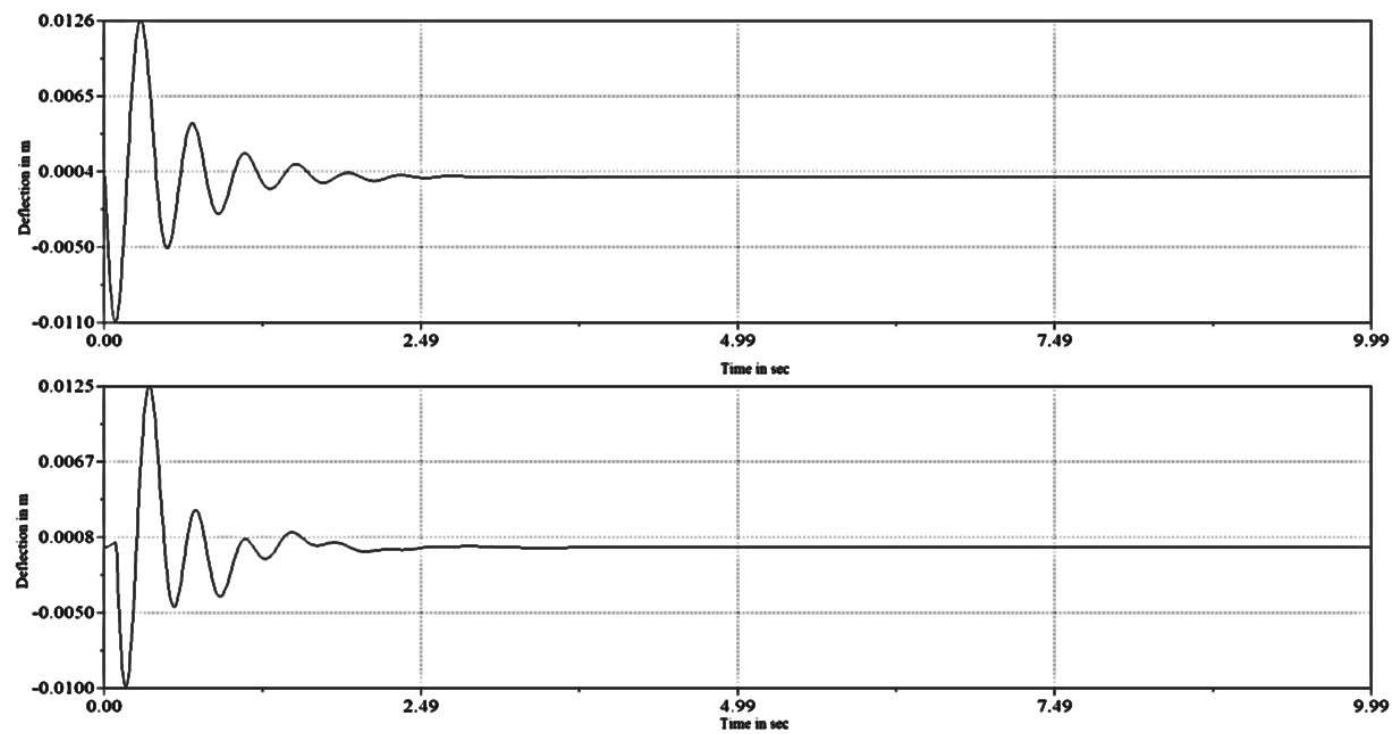

Figure 7: (a and b) Suspension Deflection at $100 \mathrm{~km} / \mathrm{h}$.

In this figure speed $100 \mathrm{Km} / \mathrm{h}$ at this speed deflection of suspension system have reduced and time taken to complete a cycle is very less. In this figure maximum suspension deflection $12.5 \mathrm{~mm}$ is gained at $.25 \mathrm{sec}$ and revers $.5 \mathrm{sec}$. this cycle is time consumed $.75 \mathrm{sec}$ they are very less time consuming and quick response provide to increasing speed 


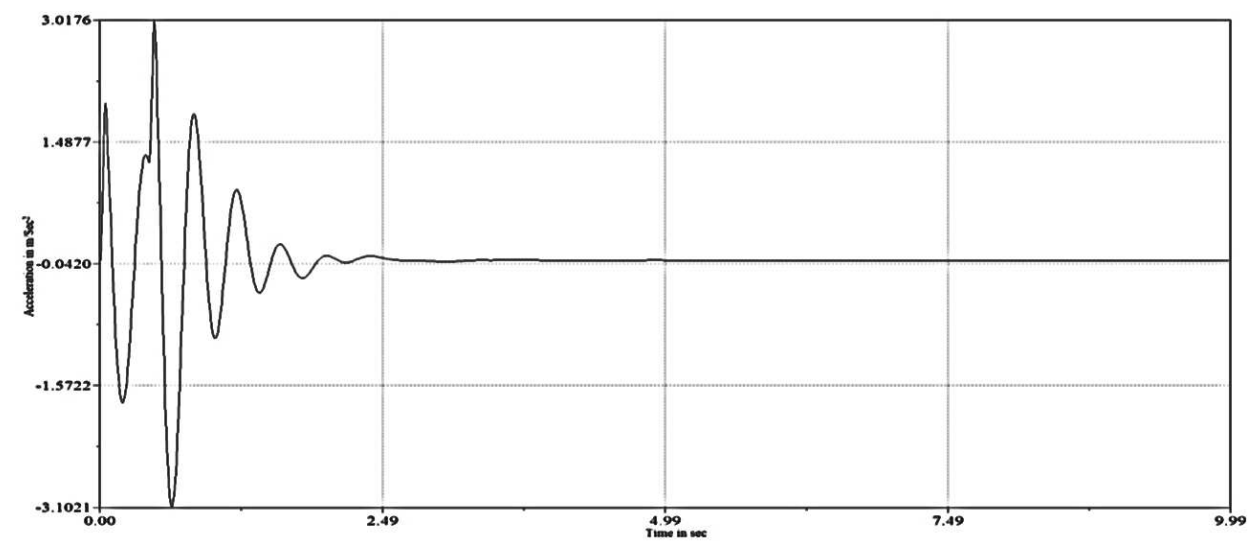

Figure 8: Suspension System Acceleration at $20 \mathrm{~km} / \mathrm{h}$.

In the figure show suspension acceleration that means suspension velocity change with respect to time. if suspension response at the velocity of $20 \mathrm{Km} / \mathrm{h}$ to traveling the maximum distance in one second. The maximum acceleration of the suspension system $3.0176 \mathrm{~m} / \mathrm{sec}^{2}$ and retardation $3.1021 \mathrm{~m} / \mathrm{sec}^{2}$ within $1 \mathrm{sec}$ response.

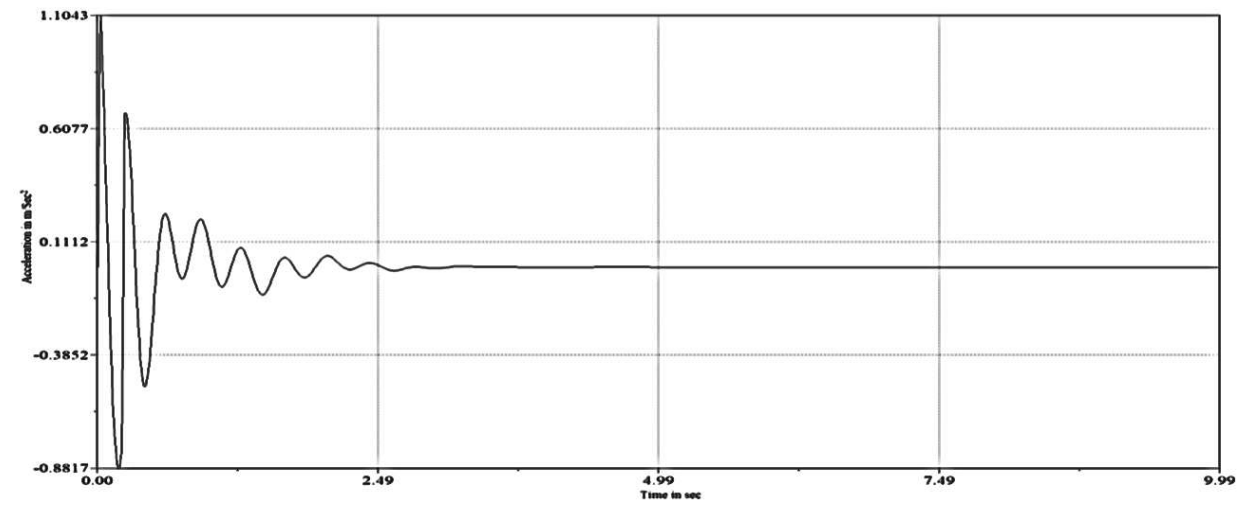

Figure 9: Suspension System Acceleration at $40 \mathrm{~km} / \mathrm{h}$.

In this figure acceleration reduced and suspension deflection also reduced at $40 \mathrm{Km} / \mathrm{h}$ speed. The maximum acceleration $1.043 \mathrm{~m} / \mathrm{sec}^{2}$ and retardation $0.8817 \mathrm{~m} / \mathrm{sec}^{2}$ within $0.5 \mathrm{sec}$ to suspension system response at $40 \mathrm{~km} / \mathrm{h}$ speed.

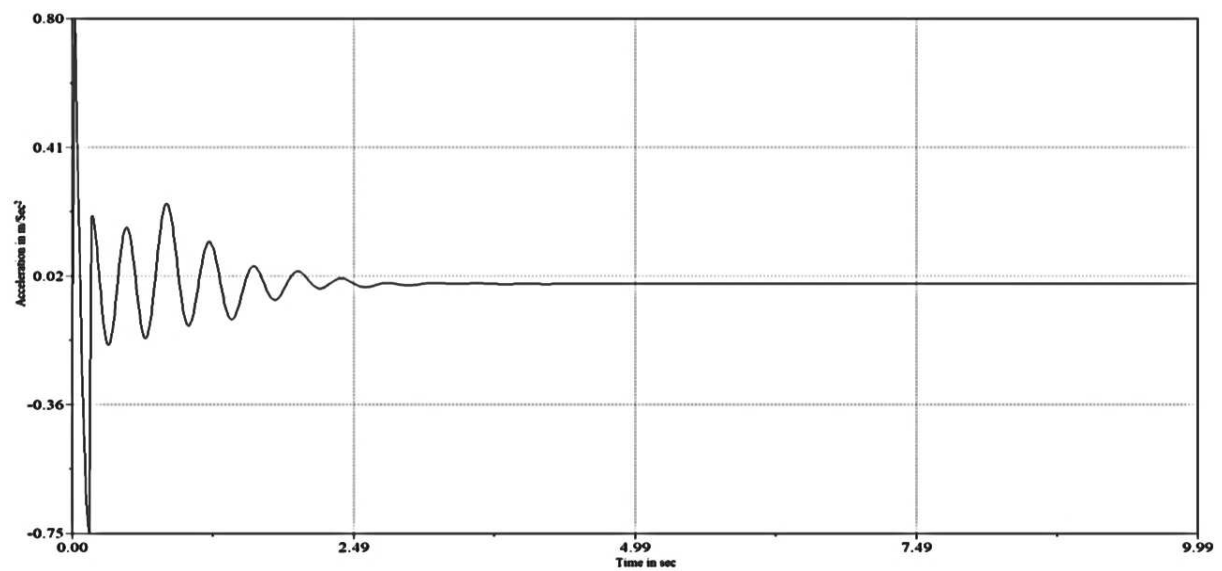

Figure 10: Suspension System Acceleration at $60 \mathrm{~km} / \mathrm{h}$.

In this figure also reduced the acceleration of suspension system but at this speed deflection of suspension system increased as compared $40 \mathrm{~km} / \mathrm{h}$ to $60 \mathrm{~km} / \mathrm{h}$. In the graph maximum acceleration $0.800 \mathrm{~m} / \mathrm{sec}^{2}$ and retardation $0.750 \mathrm{~m} / \mathrm{sec}^{2}$ within $0.25 \mathrm{sec}$ have been done the suspension work. 


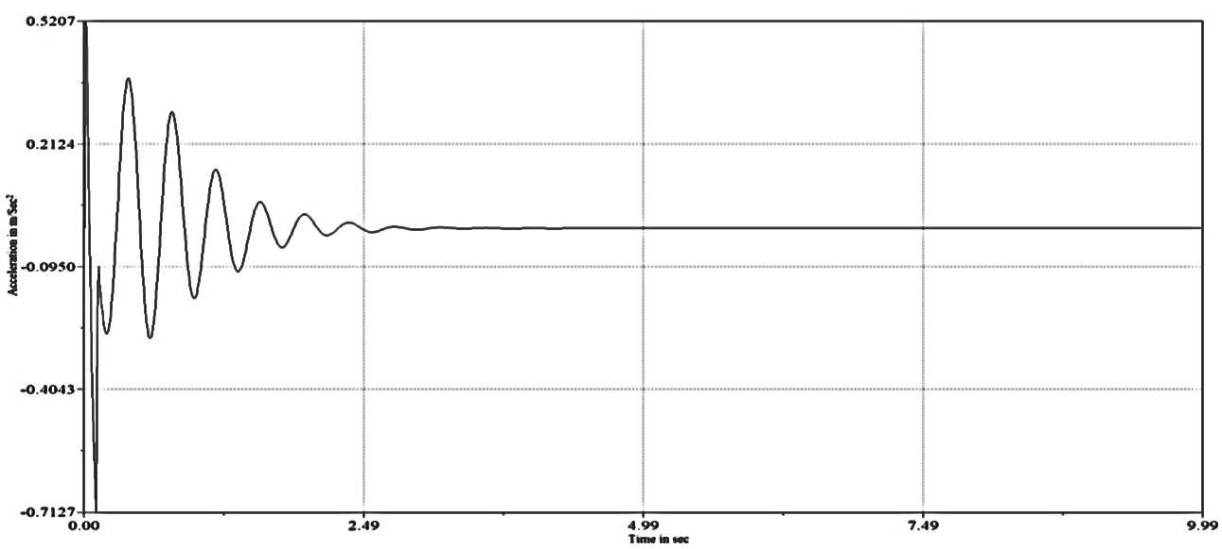

Figure 11: Suspension System Acceleration at 80km/h.

In this figure shows much reduce acceleration at $80 \mathrm{n} \mathrm{km} / \mathrm{h}$ speed. Vehicle dynamic condition at $80 \mathrm{Km} / \mathrm{h}$ speed little comfortable because the acceleration under the standard condition less than the $0.75 \mathrm{~m} / \mathrm{sec}^{2}$.So actually acceleration at $80 \mathrm{~km} / \mathrm{h} 0.5207 \mathrm{~m} / \mathrm{sec}^{2}$ but retardation of suspension $0.7127 \mathrm{~m} / \mathrm{sec}^{2}$ within $.25 \mathrm{sec}$ work has been done.

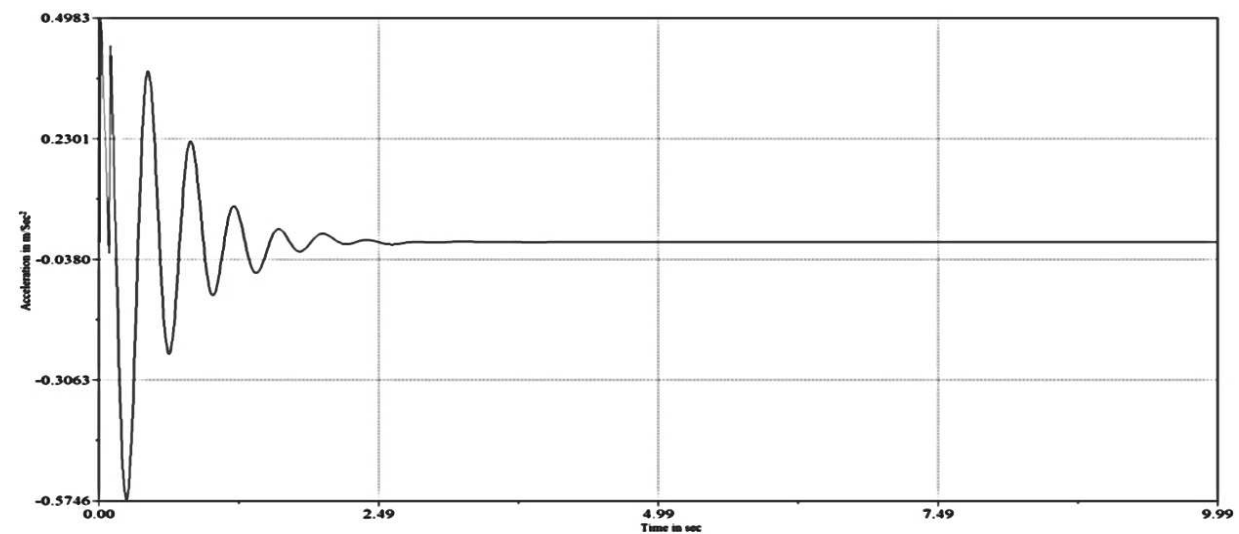

Figure 12: Suspension System Acceleration at 100km/h.

In this figure shown speeds of vehicle $100 \mathrm{~km} / \mathrm{h}$ so the velocity change with respect to time very less because the suspension acceleration is reduced at this speed of vehicle. The vehicle speed $100 \mathrm{~km} / \mathrm{h}$ maximum acceleration 0.4983 $\mathrm{m} / \mathrm{sec}^{2}$ and retardation $0.5746 \mathrm{~m} / \mathrm{sec}^{2}$ in the suspension system so the system works normally under the standard condition.

\section{RESULT AND DISCUSSIONS}

Simulation results are presented in table: 2 deflection capacity of the test specimen is $140.57 \mathrm{~mm}$. it is observed that the both the spring are capable to deflect within the range of simulated result. So the springs are safe from premature failure due to deflection i.e. physical proportions of spring are comets or as per dimension. In the value of simulation result is beyond the ability or capacity of deflection of spring than the spring will encounter the premature failure.

Table 2: Simulation Result

\begin{tabular}{|c|c|c|c|}
\hline $\begin{array}{l}\text { Speed of Vehicle } \\
\text { in } \mathrm{Km} / \mathrm{h}\end{array}$ & $\begin{array}{c}\text { Defection in Design Suspension } \\
\text { System Spring }\end{array}$ & $\begin{array}{l}\text { Deflection in Specimen (a) } \\
\text { in } \mathbf{~ m m}\end{array}$ & $\begin{array}{l}\text { Deflection in Specimen } \\
\text { (b) in } \mathrm{mm}\end{array}$ \\
\hline 20 & \multirow{5}{*}{$\begin{array}{l}\text { Maximum deflection in design } \\
140.57 \mathrm{~mm} \text { at fluctuating load }\end{array}$} & 55.30 & 68.30 \\
\hline 40 & & 26.60 & 30.50 \\
\hline 60 & & 33.90 & 33.90 \\
\hline 80 & & 40.60 & 14.40 \\
\hline 100 & & 12.60 & 12.50 \\
\hline
\end{tabular}




\section{CONCLUSIONS}

This paper has been attempted to obtain the dynamic behavior of passenger car through bond graph modeling technique and to evaluate the different parameters through simulation at various speeds. The data of premature failure may be compared with the available physical model study on this subject matter and show a considerable agreement. So, these values changed in difficult environment conditions.

The dynamic model of passenger half car had been constructed through bond graph technique. The model of suspension system contact dynamics had been developed by using bond graph technique. Required suspension displacement for better handling performance and lower vibration in car curb velocity for ride comfort has been achieved by simulation results.

\section{REFERANCES}

1. A.GonzálezRodríguez, J.M. Chacón, A. Donoso, A.G. González Rodríguezd, "Design of an adjustable-stiffness spring: Mathematical modeling and simulation, fabrication and experimental validation” Mechanics and Machine theory, vol-46 No. 12 pp. 1970-1979, (5th Jul 2011).

2. B. Pyttel, D. Schwerdt, C. Berger, "Very high cycle fatigue - Is there a fatigue limit”, International Journal of Fatigue, vol-33 No. 1 pp. 49-58 (January 2011).

3. James M. Meagher and Peter Altman, "Stresses from flexure in composite helical implantable leads",Medical Engineering and Physics, vol. 19 No. 7 pp.668-673, S1350-4533(96) 00022-7, (September 1997).

4. Alsahlani, Assaad, Mohammed K. Khashan, and Hayder H. Khaleel. "Design and analysis of coil spring in vehicles using finite elements method." Int. J. Mech. Product. Eng. Res. Dev. 8.4 (2018): 615-624.

5. Karnopp D., "Analytical results for optimum actively damped suspension under random excitation", Journalof VibrationAcoustic Stress and Reliability in Design, Vol. 111 No. 3 pp. 278-282, (01 July 1989).

6. Karnopp D.C., Margolis D.L., and Rosenberg R.C., "System dynamics, a unified approach”, 2nd edition, J Wiley New York, $N Y$, ISBN 0-471-45940-2, (1990)

7. Alsahlani, Assaad, Mohammed K. Khashan, and Hayder H. Khaleel. "Design and analysis of coil spring in vehicles using finite elements method." Int. J. Mech. Product. Eng. Res. Dev. 8.4 (2018): 615-624.

8. K. Michalczyk., "Analysis of the influence of elastomeric layer on helical spring stresses in longitudinal resonance vibration conditions", Archives of civil and mechanical engineering, vol. 13 No.1 pp. 21-26, (March 2013).

9. MA.Rosenberg R.C., Karnopp D.C., "Introduction to physical system dynamics”, McGraw Hill, New York, NY (1983).

10. Madura, Vijaya Kumar, et al. "Design and experimental study of semi active system of MR damper for vibration control." International Journal of Mechanical and Production Engineering Research and Development 8.5 (2018): 125-132.

11. Paynter, H.M., “Analysis and design of engineering systems", MIT Press, Cambridge, (1961).

12. TameshwerNath, VikasRastogi, "Quarter/Halfffull car models for passive suspension (with pid controller)", NCRAME national conference of recent advances in mechanical engineering , (2012).

13. Usmonov, B. O. T. I. R., Q. Rakhimov, and A. Akhmedov."Analysis of numerical solutions of a hereditary deformable system." International Journal of Mechanical and Production Engineering Research and Development 8 (2018): 403408. 
14. Wei Li, Tatsuo Sakai, Masami Wakitac, Singo Mimura, "Influence of microstructure and surface defect on very high cycle fatigue properties of clean spring steel”, International Journal of Fatigue, Vol. 60 pp. 48-56, (March 2013).

15. Yogesh Chaubey, Chandan Kumar, Sandeep Chauhan "Failure Analysis of Suspension System: Case Study-Tata Indica", IJSRD - International Journal for Scientific Research \& Development, Vol. 3, No. 09 pp. 1085-1090 (2015). 